\title{
The Basic Principle Of Green Supply Chain Management
}

\author{
Jinsong Zhang ${ }^{1, \text { a }}$ \\ ${ }^{1}$ Department of Industrial Engineering, Tianjin University of Technology, Tianjin, 300384, China \\ aemail: 806338091@qq.com
}

Keywords: manufacturing; Green Supply Chain Management; Green supply chain; environment

\begin{abstract}
In the 21st century human society has been developing rapidly which also brings the threat of resource depletion, serious environmental pollution and ecological imbalance. As a pillar industry of the national economy, manufacturing industry has created much material wealth for the society, while at the same time consumed large amount of resources, resulting in greater environmental pollution. Thus, in view of the environmental impact and optimizing the use of resources, the establishment of the so-called "green" supply chain and the implementation of green supply chain management in the manufacturing supply chain are important means to achieve green manufacturing. Green supply chain management is an effective way to solve the conflict between manufacturing industry and environment from the view of system and integration. This paper briefly introduces concept and nature of green supply chain, establishes the conceptual model of green supply chain, analyzes the goal of green supply chain management, and discusses the basic principle and nature of green supply chain management from the idea of sustainable development.
\end{abstract}

\section{Green supply chain}

"Environmentally Responsible Manufacturing (ERM)" research launched by Michigan State University's Manufacturing Research Association (MRC), which was funded by the National Science Foundation (NSF) with \$ 400,000, proposed the concept of green supply chain[1] in 1996 and listed it as an important research issue. In addition, the study "ESRC Global Environmental Change Program” funded by more than 20 companies such as the British Engineering and Physics Research Council (EP-SRC) and British Gasoline Corporation also listed green supply as a major research direction[2].It is foreseeable that, with the increasing popularity of supply chain and sustainable development research, green supply chain research will also become a hot topic.

There is no uniform definition of green supply chain because it is still a new topic and there is a lack of a agreed-upon definition of it.With reference to the more common formulation[3] and green manufacturing definition[4], definition of green supply chain can be summarized as "a modern management model that takes into account environmental impact and resource efficiency across the supply chain, which is based on green manufacturing theory and supply chain management technology, involving suppliers, manufacturers, vendors and users, whose purpose is to minimize the negative impact on environment and maximize resource efficiency in the whole process of a product from material acquisition, processing, packaging, storage, transportation, use to disposal.”

\section{Green Supply Chain Management(GSCM)}

Researchers at home and abroad began to study how to improve the compatibility between manufacturing and environment with the idea of supply chain management[5 8]. Green supply chain is a modern management model that takes into account environmental impact and resource efficiency across the supply chain, which is based on green manufacturing theory and supply chain management technology, involving suppliers, manufacturers, vendors and users, whose purpose is to minimize the negative impact on environment and maximize resource efficiency in the whole process of a product from material acquisition, processing, packaging, storage, transportation, use to disposal."[9].Green supply chain management, a.k.a. environmental conscious supply chain management, takes into account environmental issues in various aspects of the supply chain, 
focuses on environmental protection, and promotes the coordinated development between economy and the environment[10].The idea of integrated management and system is reflected in green supply chain management, which begun to draw attention of the academia. At the same time, green supply chain management began to play a positive role in industry and some well-known enterprises such as GM, NIKE got fruitful work with green supply chain management. However, reviewing results of the existing research for green supply chain management, the existing research results mainly focused on the green supply chain concept, system, structure, etc., without studying the basic principles of green supply chain management, that is, what are the basic principles that should be followed when managing green supply chain. The author intends to study the basic principles of green supply chain management from the perspective of system theory and integration management.

\section{Operation,control and management techniques of green supply chain management}

In the implementation process of green supply chain, technology and specific issues such as the operation, control and management of green supply chain are involved. These include green material selection, green procurement, green warehousing, green transportation, green production planning, green distribution, multi-site inventory coordination and reverse logistics (recycling and processing). It is to select materials that have little adverse impact on the ecological environment with least space occupied, resources consumed and problems produced on environment in the procurement of materials, materials and products storage, transportation, product distribution process with the help of the above-mentioned green supply chain architecture, model and evaluation system. The study of multi-site inventory coordination makes sure the least resource consumption and adverse environment damage in the process while transported materials and products to the destination. In making production plan, the issue of resource consumption and environmental impact should also be taken into account. In addition, the recovery and processing at the end of the product, that is, reverse logistics, is also an important research topic.

\section{Basic principle of green supply chain operation management}

\section{Symbiotic principle}

The symbiosis between human society and nature is an objective law that any economic system must follow[11] and which is also one of the basic principles that green supply chain management should follow. The connotation of symbiosis principle in the operation of green supply chain can be explained by further analysis of the composite function of green supply chain operation target. Assuming that $\mathrm{R}, \mathrm{T}$, and $\mathrm{H}$ affect the operation of the green supply chain through the three subsystems of (2), (3) and (4) respectively, there are

$$
\begin{aligned}
& \text { GSC }=\mathrm{f}(\mathrm{P}(\mathrm{R}, \mathrm{T}, \mathrm{H}), \mathrm{W}, \mathrm{E}) \\
& \mathrm{GSC}=\mathrm{f}(\mathrm{P}, \mathrm{W}(\mathrm{R}, \mathrm{T}, \mathrm{H}), \mathrm{E}) \\
& \mathrm{GSC}=\mathrm{f}(\mathrm{P}, \mathrm{W}, \mathrm{E}(\mathrm{R}, \mathrm{T}, \mathrm{H}))
\end{aligned}
$$

Equations (5) to (7) respectively draw partial derivative for $\mathrm{R}, \mathrm{T}, \mathrm{H}$, and make it equal to zero, then there are

$$
\begin{aligned}
& \frac{\partial G_{S C}}{\partial P} \frac{\partial P}{\partial R}=\frac{\partial G_{S C}}{\partial W} \frac{\partial W}{\partial R}=\frac{\partial G_{S C}}{\partial E} \frac{\partial E}{\partial R}(8) \\
& \frac{\partial G_{S C}}{\partial P} \frac{\partial P}{\partial T}=\frac{\partial G_{S C}}{\partial W} \frac{\partial W}{\partial T}=\frac{\partial G_{S C}}{\partial E} \frac{\partial E}{\partial T}(9) \\
& \frac{\partial G_{S C}}{\partial P} \frac{\partial P}{\partial H}=\frac{\partial G_{S C}}{\partial W} \frac{\partial W}{\partial H}=\frac{\partial G_{S C}}{\partial E} \frac{\partial E}{\partial H}(10) \\
& \text { Change equation (8) and there are }
\end{aligned}
$$




$$
\begin{aligned}
& \frac{\partial P}{\partial R} / \frac{\partial W}{\partial R}=\frac{\partial G_{S C}}{\partial W} / \frac{\partial G_{S C}}{\partial P} \\
& \frac{\partial P}{\partial R} / \frac{\partial E}{\partial R}=\frac{\partial G_{S C}}{\partial E} / \frac{\partial G_{S C}}{\partial P}
\end{aligned}
$$

Equation(11) shows that ratio of economic effect to environmental improvement caused by change in the resource utilization of members in the supply chain is equal to the contribution rate of environmental improvement to the development of green supply chain as a whole. Similarly, equation (12) shows that the ratio of economic effect to the increase in welfare for the change in resource utilization of members in the supply chain is equal to the contribution rate of welfare to the development of green supply chain as a whole, which indicating that there is a symbiotic relationship among subsystems within green supply chain. At the same time it can be concluded from equations (2) and (3) that: if the value of $\partial E / \partial R$ is large, the value of $\partial G_{S C} / \partial E$ is small; similarly, if the value of $\partial W / \partial R$ is large, the value of $\partial G_{S C} / \partial W$ is small. Thus, there is a mechanism for checks and balances in the operation of green supply chains: if a variable has a significant impact on the output of one subsystem in the supply chain, the impact of the subsystem on green supply chain system tends to be weakened.

Similarly, the analysis can be made to equation (9) and equation (10), and the conclusions are similar. Thus, in order to achieve the three major goals of green supply chain operation, the relationship between the three subsystems in green supply chain operation should be fully coordinated. In general, the goal of one subsystem should not be emphasized with sacrifice to goals of other subsystems.

\section{Principle of circulation}

Principle of circulation means that energy is cycled between subsystems in green supply chain until it becomes entropy. Entropy is the sum of energy that can not be consumed again. The greater the entropy, the greater the sum of energy consumed by human activities, indicating the greater negative impact of its activity on the environment. The principle of circulation is derived from the second law of thermodynamics in physics. For the actors in green supply chain, their activities are also subject to the principle of circulation: it is impossible for any economic activity or social activity to reduce the total entropy of the earth, but only to accelerate or delay the increase in the total entropy. The principle of circulation is a basic law green supply chain operation must follow. In order to improve the compatibility of members' behavior in the chain to the environment, it is necessary to adopt environment-compatible pollution prevention technology, green manufacturing technology and waste minimum quantification technology in all aspects, which are beneficial to enter negative entropy flow in the whole supply chain and realize the process of delaying increasing of the entropy.

When it comes to the energy cycle process in the GSC, first of all, the supply chain manufacturers manufacture products, complete the energy's (resources') movement in the production of GSC, resulting in the provide of consumer goods for consumption subsystem, which in the meanwhile produce waste, pollution and entropy; and in order to reduce the increase of entropy in this part, green manufacturing technology, and materials and production technique compatible with environment in GSC are required. Second, it shows that when energy in GSC enters into consumption system, through cycle between consumption and recycle results in the improvement of welfare level for consumers in the supply chain, while entropy is produced along with part of the consumption. In this part, through the use of green consumption patterns and emphasizing the recovery of resources can generate negative entropy flow and then weaken the amount of entropy generated. Third, when energy enters into environment subsystem, with its own regulatory function, environmental purification and biological growth, nature can turn waste into a new source of resources, increase the stock of resources, and thus achieve increase of negative entropy. Energy circulation of each subsystem in GSC affects GSC management objectives. If GSC's overall energy is strengthened, GSC can effectively achieve three basic objectives mentioned 
above, otherwise, the energy will decrease due to the increase of entropy. Therefore, it is necessary to adopt green manufacturing technology and green consumption patterns to strengthen the increase of negative entropy, and then achieve management objectives of green supply chain.

\section{System openness principle}

System openness principle means that the interaction between system and environment is a relationship of dynamic transformation, that is, there is often material, energy and information exchange between the two. Ilya Prigogin[12] holds that, entropy dSe produced by the exchange of energy and material between system and the outside world and the entropy dSi produced in the irreversible process within the system should be considered, that is, open system has $\mathrm{dS}=\mathrm{dSe}+\mathrm{dSi}$, dSe is entropy change caused by material and energy exchange between system and the outside world, which is either positive or negative; dSi is the entropy change caused by the irreversible process within the system; the amount is always positive. If the outside world provides sufficient negative entropy flow $\mathrm{dSe}<0$, and $\mathrm{dSe}>\mathrm{dSi}$, then it is possible that $\mathrm{dS}<0$, that is, without violating the second law of thermodynamics conditions, the nonlinear system away from the balance can reduce the total entropy by negative entropy flow so that the system can turn from disorder into order, that is, the state of the dissipative structure.

The openness principle of system requires that in the operation of green supply chain, it is necessary to adjust the composition of each subsystem according to change of the external environment and the internal changes of the system; such as changing values, ethics, business philosophy of members in the supply chain, adjusting product mix and consumption structure of the supply chain, using resources and technology more environmentally-friendly, adjusting members composition of the supply chain to ensure realization of target in green supply chain.

\section{Conclusion}

The contradiction between population, resources and the environment is increasingly prominent. Manufacturing is plays an important role in resource shortages and environmental pollution. Human sustainable development and survival requires to improve compatibility of manufacturing and environment and achieving compatibility of manufacturing and environment is an inevitable trend for the development of modern manufacturing industry; which needs the employment of green supply chain principles. At the same time, green supply chain management is an effective way to solve the conflict between manufacturing and environment from the idea of system and integration. Based on the idea of sustainable development, the conceptual model of green supply chain is established, and the goal of green supply chain management analyzed. Upon this, basic principles of green supply chain management, principle of symbiosis, principle of circulation and principle of system openness are basic principles that should be followed to the implementation of green supply chain management, and green supply chain management based on these three principles is more effective.

\section{References}

[1] Handfield R B.Green Supply Chain:Best Practices From the Fumiture Industry. Proceedings Annual Meeting of the Decision Sciences Institure,USA,1996(3):1295 1297.

[2] Green Supply Chain Management. http: //www.egr.msu.edu/case/mrc/mrcprojects. html.

[3] Han Jian,Wu Cheng,Fan Yushun.Technology Status and Development Trend of Supply Chain Modeling and Management.Computer integrated manufacturing system CIMS,1998,4(4):8 14.

[4] Liu Fei,Zhang Hua,Yue Honghui.Green Manufacturing - Sustainable Development Model of Modern Manufacturing Industry.China Mechanical Engineering,1998,9(6): 76 78.

[5] Lipppman T. Supply chain environmental management: element for success[ J]. Environmental Management, 1999,(6): 175 182. 
[6] Beamon B M.Designing the green supply chain[J].Logistics Information Management,1999,12(4):332 342.

[7] Wang Nengmin,Sun Linyan,Wang Yingluo.Supply Chain Management Based on Green Manufacturing[J].China Mechanical Engineering,2002(23):2016 2018.

[8] Wang Nengmin,Yang Tong.Design of Supply Chain Based on Green Manufacturing[J].Manufacturing automation,2001(4):10 52.

[9] Dan Bin,Liu Fei.Research on Green Supply Chain and Its System Structure[J]. China Mechanical Engineering,2000,(11):1232 1234.

[10] Jiang Hongwei,Han Wenxiu.Green Supply Chain Management: Trends in Business Management[J].China 's population, resources and environment.2000,10(4):90 92.

[11] Liu Zhepei,Pan Jiahua.Sustainable Development Theory and "China's Agenda 21", A Strategic Study on China 's Sustainable Development in the 21st Century[M].Beij- ing:Tsinghua University Press,2001.36 49.

[12] Llya Prigogine.Explore the complexity[M].Chengdu:Sichuan Education Press, 2010. 